\title{
MEKANISME AUS PAHAT PUTAR PADA PEMESINAN MAGNESIUM AZ31
}

Gusri Akhyar Ibrahim

Dosen

Jurusan Teknik Mesin, Fakultas Teknik Universitas Lampung gusri.akhyar@eng.unila.ac.id

Suryadiwansa Harun Dosen Jurusan Teknik Mesin, Fakultas Teknik Universitas Lampung Suryadiwansa.harun@eng.unila.ac.id
Magnesium alloy is one of the most popular light material which was used in biomedical. Magnesium alloy is very light, resistant to corrosion and good biocompatible. However, magnesium alloy is flammable, so it is effortless to burn. This research investigated the wear mechanism at the edge rotary cutting tool. The cutting tool used in this experiment is carbide insert with a diameter of $16 \mathrm{~mm}$. Pressured cooling air was used to reduce wear progression. The cutting parameters selected were workpiece speed at 80, 120 and $180 \mathrm{~m} / \mathrm{min}$, feed rate at $0.10,0.15$ and $0.20 \mathrm{~mm} / \mathrm{rev}$., tool speed at 25, 50 and $75 \mathrm{~mm} / \mathrm{min}$, and constant depth of cut at $0.3 \mathrm{~mm}$. Tool wear and wear mechanism of the cutting tool were measured by using a microscope with particular magnification. Maximum wear on the carbide cutting tool was $0.449 \mathrm{~mm}$, which was achieved at the end of tool life. Dominant wear mechanism occurred at the cutting tool was abrasive wear. Some scratches were observed at the edge of the tool as a result of hard particles. Another wear type that occurred was crater wear at the top area of the insert. The wear on the cutting tool was due to the excessive heat generated during the machining process, which was due to friction between the cutting tool and workpiece material.

Keywords: Magnesium, Carbide, Wear Mechanism, Rotary Tool, Abrasive

\section{PENDAHULUAN}

Pengembangan material maju secara terus-menerus dikembangkan untuk mendapatkan sifat istimewa yang sesuai kebutuhan di bidang tertentu. Perkembangan ini seiring dengan tuntutan kebutuhan industri manufaktur yang semakin hari semakin meningkat, tertutama di beberapa bidang pokok, antaranya adalah bidang kesehatan dan industri manufaktur [1]. Rekayasa material ringan dikembangkan secara besar-besaran di bidang industri pesawat terbang untuk mengurangi beban sewaktu beroperasi. Sementara itu, di bidang biomedik juga dikembangkan material ringan untuk mendapatkan biokompatibel dengan tubuh manusia. Saat ini, material ringan yang sedang dikembangkan secara meluas di bidang industri manufaktur yaitu paduan magnesium karena material magnesium dijadikan sebagai bahan alternatif pengganti besi dan baja. Material paduan magnesium ini memiliki sifat yang unggul dibandingkan dengan material lain antaranya adalah sangat ringan, tahan korosi dan konduktifitas yang baik. Selain itu magnesium dan paduannya juga memiliki rasio berat terhadap kekuatan yang baik [1,2].

Implementasi paduan magnesiun telah dilakukan di beberapa bidang, satu diantaranya adalah industri manufaktur, dimana magnesium digunakan sebagai komponen otomotif, elektronik dan biomedik. Di bidang otomotif, magnesium biasanya digunakan untuk material komponen mesin yang terletak di bagian depan kendaraan, karena memiliki sifat yang ringan sehingga pengurangan berat mesin dan juga tahan terhadap panas. Dengan demikian dapat meningkatkan kinerja dan kesetimbangan berat [3]. Penggunaan magnesium juga pada produk elektronik seperti laptop, notebook, kamera dan lain sebagainya. Sifat pengantar panas yang baik dan tahan terhadap karat menjadi alasan utama untuk hal ini. Bidang yang lain yang sedang banyak dikembangkan adalah biomedik seperti komponen pengganti tulang, pin untuk menguatkan tulang, pelat untuk sambungan tulang. Sifat biokompatibel dan mampu luluh di dalam tubuh menjadi penting karena magnesium tidak menjadi benda asing di dalam tubuh dan tiada diperlukan operasi secara berulang [2].

Paduan magnesium sudah digunakan sebagai pengganti komponen yang terbuat dari aluminium dan 
titanium, dimana saat ini memiliki harga yang relatif mahal. Dengan demikian penggunaan material paduan magnesium tersebut dapat mengurangi biaya bahan baku komponen pada produksi [4]. Bahkan akhir-akhir ini perkembangan penggunaan paduan magnesium lebih banyak di fokuskan di bidang material biomedik. Karena sifatnya yang mirip dengan tulang dan tidak berbahaya di dalam tubuh serta material ini bisa luluh dalam tubuh. Oleh karena itu, paduan magnesium dikembangkan sebagai material pengganti tulang manusia yang telah rusak karena mengalami kecelakaan [5,6].

Bagaimanapun juga, usaha peningkatan produktifitas melalui peningkatan kecepatan potong dan kecepatan makan terkendala oleh sifat ketermesinan (machineability) magnesium yang tidak menguntungkan. Titik nyala yang rendah telah menimbulkan pengapian lebih awal pada saat proses pemotongan berlangsung. Pengapian atau terbakarnya geram dapat terjadi pada temperatur pemotongan telah mencapai $400-600^{\circ} \mathrm{C}[2,3]$. Peningkatan kecepatan potong dan kecepatan pemakanan telah memberikan kontribusi langsung terhadap pemingkatan temperatur yang ditimbulkan, sehingga memiliki dampak terhadap temperatur pemotongan baik pada sisi pahat potong ataupun benda kerjanya [7].

Keuasan pahat yang terjadi selama proses pemotongan, secara dominan disebabkan oleh temperatur pemotongan yang tinggi, dimana temperatur tersebut sebagai akumulasi panas yang timbul dari gesekan antara benda kerja dan pahat potong dan antara pahat potong dan geram. Temperatur pemotongan yang terlalu tinggi sering kali menjadi sumber utama kerusakan mata pahat potong. Hal ini secara langsung berdampak terhadap prestasi pahat, daya tahan pahat bahkan berkorelasi langsung dengan biaya produksi. Oleh karena salah satu metode yang diimplementasikan mencegah kerusakan pahat lebih awal adalah dengan menggunakan pahat berputar pada proses pemesinan bubut [4]. Diharapkan dengan cara menggunakan pahat berputar saat memotong benda kerja, dapat dipastikan kalau pahat memotong benda kerja pada sisi potong yang berbeda-beda. Dengan demikian, akumulasi panas yang di hasil tidak berada pada satu titik potong. Ada waktu jedah yang memungkinkan pahat mengalami pendinginan

Usaha untuk mengetahui pengaruh temperatur pemotong terhadap mekanisme pembentukan aus pada pahat potong dilakukan dengan cara mengambil foto SEM permukaan yang mengalami aus dan mengamati ciri ausnya. Juga dikatakan bahwa semakin tinggi temperatur yang terakumulasi pada pahat potong, maka aus yang terjadi semakin besar, bahkan beberapa kasus muncul jenis aus yang berbeda [8]. Pada penelitian yang dikemukakan oleh Haryanto [8] bahwa temperatur pemotongan mencapai $176,2^{\circ} \mathrm{C}$, sedangkan jenis aus yang terjadi didominasi oleh jenis aus abrasif. Bahkan disebutkan juga aus abrasif ini terjadi diakibatkan oleh goresan permukaan oleh partikel yang tajam, sehingga permukaan pahat potong menjadi tidak seragam.

Dalam penelitian Ibrahim et al. [9] menyatakan bahwa pada waktu pemesinan bubut material magnesium menggunakan pahat karbida, didapatkan jenis aus abrasif secara dominan. Hal itu diperoleh karena menggunakan pahat dengan geometri sudut kecil dengan kecepatan potong yang relatif rendah. Pada penelitian tersebut digunakan kecepatan potong $88,39 \mathrm{~m} / \mathrm{min}$ dan menggunakan media pendingin untuk mengurangi temperatur pemotongan. Sebagaimana dikatakan bahwa temperatur pemotongan terakumulasi sebagai akibat dari gesekan antara benda kerja dan pahat pahat potong dan pahat potong dan geram. Hal ini yang menyebabkan kecepatan potong perlu dikendalikan, supaya temperatur yang dihasilkan rendah. Secara tiori, aus abrasif berlangsung pada temperatur rendah, sedangkan jika temperatur ditingkatkan, sampai pada satu kondisi tertentu maka aus yang terjadi adalah aus kimia. Aus kimia ini terbentuk, lantaran material pahat ataupun material benda kerja berinteraksi sehinnga permukaan benda menjadi lebih halus. Permukaan halus merepresentatifkan nilai kekasaran permukaan benda kerja yang dimesin [10].

\section{METODE DAN BAHAN}

Proses pemesinan dilakukan menggunakan mesin bubut dan pahat putar berbahan karbida, sedangkan material benda kerja adalah paduan magnesiun AZ31. Paduan magnesium ini mengandung sekitar 3\% aluminium dan kurang dari $1 \%$ zinc serta selebihnya adalah magnesium. Material ini memiliki konduktivitas termal sebesar $77 \mathrm{~W} / \mathrm{mK}$, titik cair sebesar $891 \mathrm{~K}$, modulus Young sebesar $45 \mathrm{kN} / \mathrm{mm}^{2}$ dan kapasitas panas sebesar $1.02 \mathrm{~J} . g k$. Metode sistem pahat putar dan udara dingin keluaran vortex tube bertekanan 6 bar digunakan untuk mengurangi temperatur yang dihasilkan selama proses pemotongan. Pahat putar yang digunakan jenis pahat karbida yang dilapisi dengan lapisan tipis, sebagaimana dapat dilihat pada Gambar 1. 

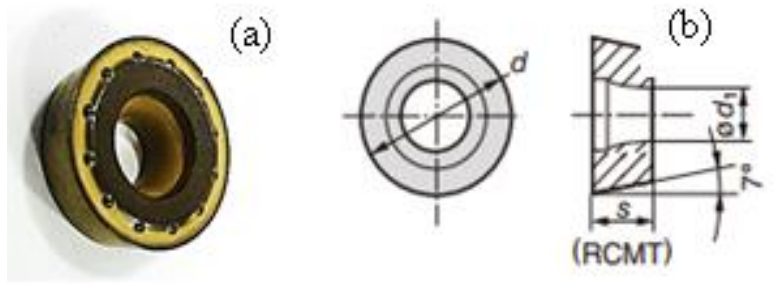

Gambar 1: (a) Pahat putar berjenis insert dengan tipe RCMT, (b) Tampak 2D insert RCMT

Pahat yang digunakan pada sistem pahat putar adalah pahat insert tipe RCMT dengan material karbida berdiameter $16 \mathrm{~mm}$. Pada bagian samping, pahat ini memiliki sisi yang sedikit tirus yang memiliki fungsi untuk mempermudah aliran chip pada saat pemotongan. Pahat karbida yang digunakan mengandung Tungsten (W) sebesar 94\%, Karbon (C) sebesar <6\% dan Cobalt (Co) sebagai pengikat (binder). Secara detail spesikasi pahat karbida yang digunakan adalah sebagaimana yang ditunjukan pada Tabel 1.

Tabel 1. Spesifikasi Pahat putar

\begin{tabular}{cc}
\hline Parameter & Keterangan \\
\hline Merk & Sumitomo \\
\hline Tipe & RCMT \\
\hline Seri & 1606MON-RX \\
\hline Jenis & Insert \\
\hline Material & Carbide \\
\hline Diameter Pahat & $16 \mathrm{~mm}$ \\
\hline Tebal pahat & $6,35 \mathrm{~mm}$ \\
\hline
\end{tabular}

Pada perangkat sistem pahat putar dipasang vortex tube cooler yang digunakan untuk mendinginkan pahat putar dengan memanfaatkan udara dingin bertekan. Nozel diarahkan ke sisi potong pahat putar agar mendapatkan suplai udara dingin yang cukup dan langsung mengenai sisi potong. Secara detail mekanisme pendinginan pahat putar dengan Vortex tube sebagaimana yang ditunjukan pada Gambar 2. Pengambilan data berupa aus pahat potong dilakukan dengan menggunakan mikroskop dengan tingkat perbesaran hingga mencapai 80x. Jenis aus diamati melalui foto mikroskop dan dilakukan indentifikasi terhadap fenomena dan sifat aus. Data hasil penelitian ini diambil selama proses pemotongan dengan kondisi yang beragam antaranya adalah kecepatan potong 80,120 , dan $160 \mathrm{~m} / \mathrm{min}$, kadar pemakanan $0,10,0,15$, dan $0,20 \mathrm{~mm} / \mathrm{rev}$, kedalaman potong $0,3 \mathrm{~mm}$, dan kecepatan putaran pahat 25,50 , dan $75 \mathrm{~m} /$ menit.
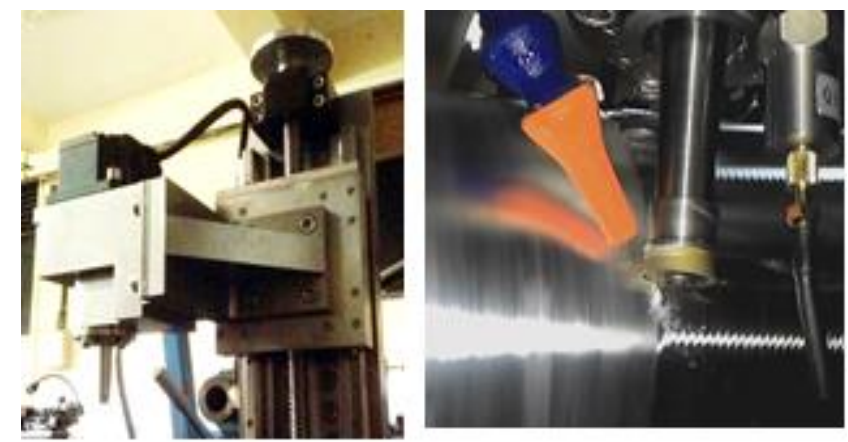

Gambar 2: Sistem pahat putar dan perangkat vortex tube pada mesin bubut

\section{HASIL DAN DISKUSI}

\subsection{Progres Aus Pahat Putar}

Berdasarkan hasil pengujian dapat diamati bahwa pertumbuhan keausan pahat putar cenderung mengalami peningkatan yang berbeda-beda disetiap kondisi parameter pemotongan.. Mekanisme pertumbuhan keausan yang terjadi karena adanya partikel keras pada benda kerja yang bergesekan dengan aliran material benda 
kerja atau yang disebut proses abrasif [11]. Aus abrasif ini menyebabkan keausan tepi pahat yang akan tumbuh dengan bertambahnya waktu. Pola pertumbuhan aus pahat yang tejadi yaitu dimulai dengan pertumbuhan yang relatif cepat terjadi di awal pemotongan diikuti pertumbuhan linier yang setara dengan bertambahnya waktu pemotongan. Pada awal pemotongan seringkali aus terjadi dalam selang waktu yang relatif cepat karena di awal pemotongan keadaan ujung pahat masih baru, sehingga kerusakan ujung mata pahat terjadi dengan mudah dan cepat. Ujung pahat pahat yang tajam, bisa bergesekan dengan benda kerja, akan mengalami kerusakan sehingga perubahan ujung mata pahat berlangsung dengan cepat [12].

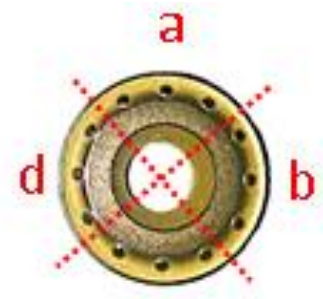

C

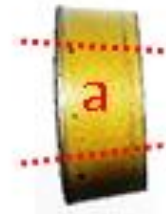

Gambar 3: Sisi potong pahat putar yang mengalami aus di sekeliling mata pahat

Gambar 3 menunjukan bahwa sisi potong pahat putar yang mengalami aus berkelanjutan, dimana sekelilingnya mengalami perubahan bentuk karena terdeformasi. Oleh karena itu, untuk mengamati mekanisme dan aus pahat potong, maka bagian yang mengalami aus berada di sepanjang ujung mata pahat. Ujung mata pahat yang bersentuhan dengan benda kerja atau yang memotong benda kerja berada di sekeliling lingkar ujung mata pahat. Oleh karena itu, untuk mengamatinya dilakukan pengamatan di sepanjang sisi tersebut. Tidak semua sisi di sepanjang mata pahat yang mengalami aus merata, akan tetapi aus yang terjadi beragam baik kedalamannya ataupun panjang ausnya [13]. Untuk memudahkan dalam pengamatan dilakukan pangambilan gambar pada sisi yang mangalami aus paling banyak. Berikut merupakan area yang mengalami aus pada sisi ujung mata pahat yaitu titik a, b ,c dan d.

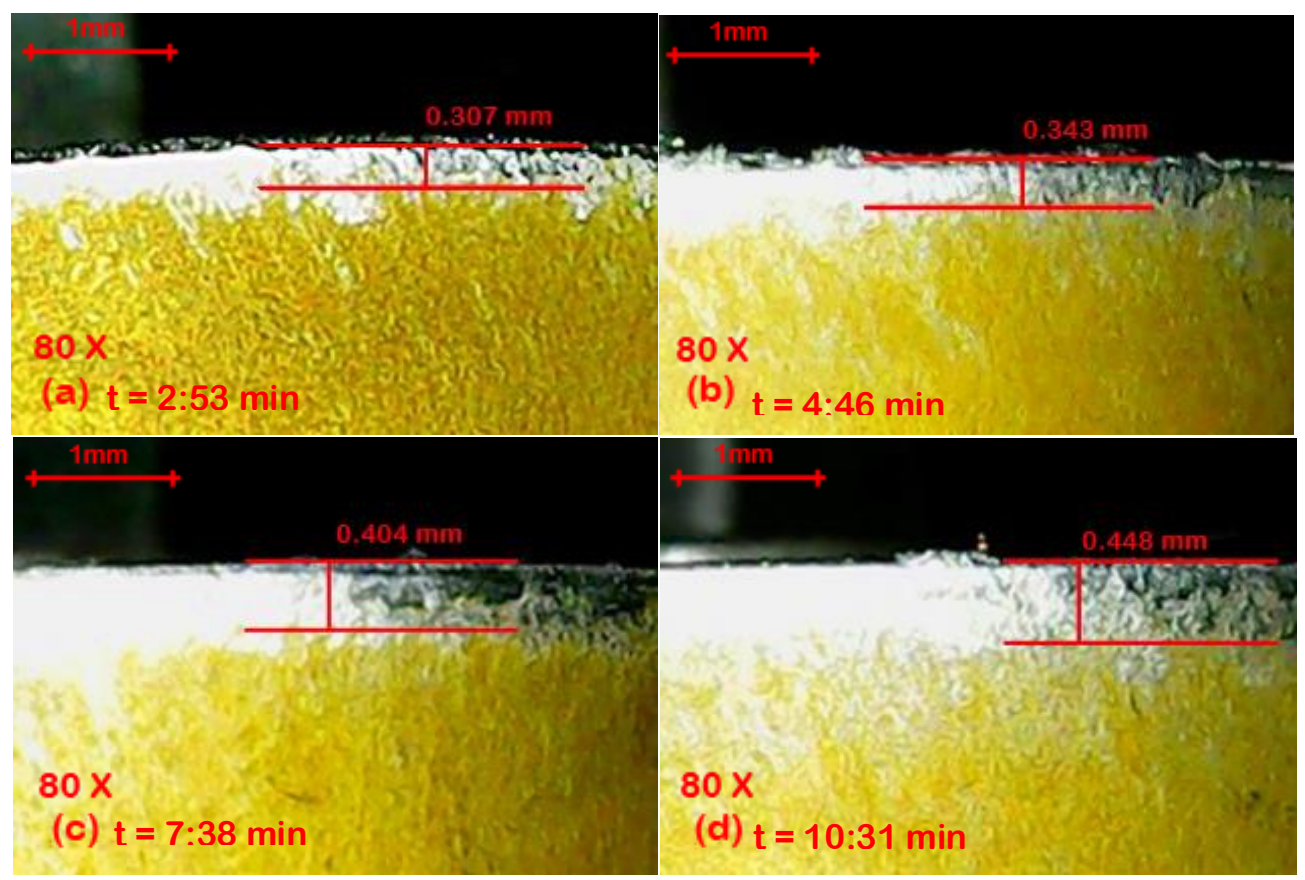

Gambar 4: Progres aus yang berlangsung di beberapa titik ujung mata pahat putar

Gambar 4. menunjukan progres aus yang terjadi di sepanjang ujung mata pahat, di mana diambil aus yang paling besar dengan nilai laju keausan rata-rata 13,5\% dan aus akhir yaitu sebesar 0,448 mm dengan waktu 10.31 min. Keadaan aus ini terjadi pada kondisi pemotongan dengan kecepatan putaran benda kerja (Vw) 160 $\mathrm{m} / \mathrm{min}$, kecepatan gerak makan $0,15 \mathrm{~mm} / \mathrm{rev}$, kecepatan potong pahat putar $(\mathrm{Vt}) 75 \mathrm{~m} / \mathrm{min}$ dan kedalaman 
potong 0,3 $\mathrm{mm}$. Secara dominan aus pada ujung pahat adalah aus abrasif, dimana permukaan muka mengalami goresan benda tajam. Permukaan muka pahat yang mangalami aus pertama kali adalah pada bagian yang berdekatan dengan sisi mata pahat, selanjutnya pergerakan aus menuju bagian bawah sisi mata pahat. Aus abrasif yang terjadi disebabkan oleh goresan partikel mata pahat yang terlepas dan berada pada celah antara benda kerja dan mata pahat. Bagaimanapun juga aus yang pertama kali terjadi adalah terbuangnya lapisan pahat potong karena gesekan dengan benda kerja. Pada Gambar 4 dapat diamati bahwa terbuangnya lapisan pahat potong ditandainya dengan terbuangnya warna kuning pada permukaan pahat potong, karena warna kuning pada permukaan pahat potong merupakan lapisan tipis yang diperuntukan untuk meningkatkan kemampuan daya gesek pahat.

Mulai dari awal pembentukan aus hingga aus mencapai titik batasnya, jenis uas yang terjadi adalah abrasif. Bagaimanapun juga, pada bagian tertentu, aus yang berbentuk adalah berupa lapisan (coating) terkelupas. Pada sisi muka pahat potong, ada bagian berwarna putih yang tidak merata. Keadaan yang demikian ditandai sebagai permukaan pahat atau lapisan pahat potong mengalami aus. Aus yang terbentuk, diakibatkan oleh gesekan kecil antara permukaan pahat yang tidak tajam dengan permukaan benda kerja. Aus adhesif bisa diamati dengan adanya material yang melekat pada permukaan pahat. Ini adalah sebagai akibat adanya proses adhesif (melekat) sebelum permukaan pahat tergores oleh partikel keras yang tidak tajam. Adanya material yang melekat berkaitan dengan sifat magnesium yang mudah bereaksi dengan material lain dan magnesium yang bersifat ulet.

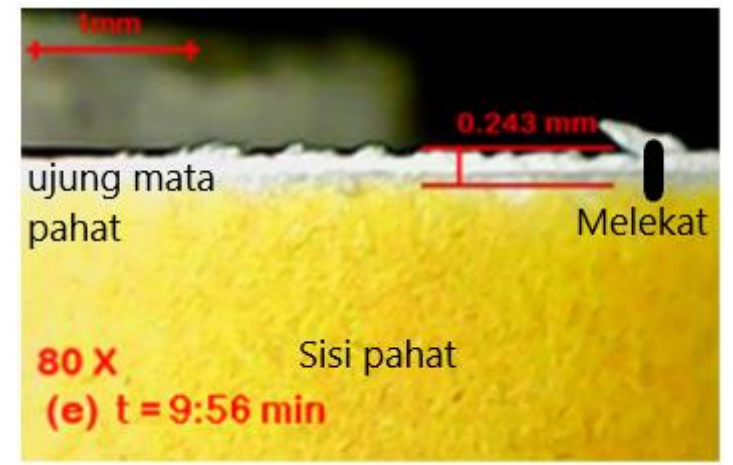

Gambar 5. Aus adhesif pada ujung mata pahat karbida.

Gambar 5. menunjukan jenis aus yang diakibatkan oleh adanya material yang melekat pada ujung mata pahat, dimana kemudian bahan yang melekat mengakibatkan material pahat terlepas dari bahan induknya. Karena awal terjadinya proses aus diakibatkan oleh sifat reaktif dan melekatnya material lain, maka progres ausnya dinamakan sebagai aus adhesif. Daya ikat material yang melekat lebih besar dibandingkan dengan daya material pahat, sehingga material terlepas dari ikatan utamanya. Aus yang demikian terjadi pada putaran benda kerja $(\mathrm{Vw}) 80 \mathrm{~m} / \mathrm{min}$, gerak makan $0,1 \mathrm{~mm} / \mathrm{rev}$, kecepatan potong pahat putar $(\mathrm{Vt}) 50 \mathrm{~m} / \mathrm{min}$ dan kedalaman potong $0,3 \mathrm{~mm}$. Hal ini terjadi pada kecepatan potong rendah, sehingga sangat mungkin diakibatkan oleh panas yang tidak cukup untuk ikatan melepaskan ikatannya. Material yang terlepas melekat, akibat dari daya reaktif tinggi dari bahan magnesium.

\subsection{Aus Muka di Sekeliling Mata Pahat}

Pada proses pemesinan paduan magnesium menggunakan sistem pahat putar telah didapati fenomena, dimana keausan mata pahat yang terjadi di sekeliling pahat putar tidak seragam. Hal itu ditandainya dengan perbedaan luasan area yang mengalami aus, di setiap sisi di sepanjang mata pahat. Sebagaimana yang dapat dilihat pada Gambar 6 bahwa di satu titik, aus sudah mencapai luasan yang besar (6b), sedangkan pada titik yang lain, baru mencapai luasan setengahnya (6d). Perbedaan luasan aus yang demikian, disebabkan oleh tidak seragamnya gaya pemotongan di sepanjang pemotongan. Boleh jadi, hal ini disebabkan oleh tekanan yang tidak sama selama proses pemotongan berlangsung, dikarenakan oleh putaran pahat ataupun putaran benda kerja tidak sentris. Boleh jadi juga, keadaaan tersebut disebabkan oleh, aus pahat potong terjadi tidak seragam sehingga memicu kepada tidak seimbangnya putaran atau tidak sentris [15]. 

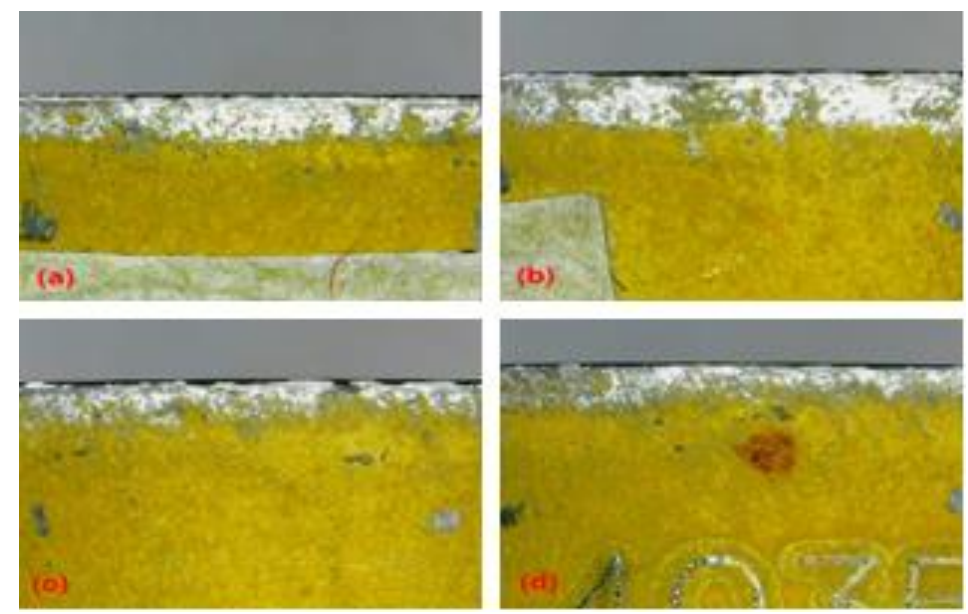

Gambar 6. Fenomena terjadinya aus tepi pahat putar

Sebagaimana dijelaskan oleh peneliti sebelum ini [16] bahwa ada beberapa faktor yang menyebabkan keausan di sekeliling mata pahat tidak seragam, antaranya putaran pahat yang tidak sentris (run out). Ia juga mengatakan bahwa rasio putaran run out merupakan penyimpangan suatu komponen terhadap sumbu putar. Dengan demikian rasio perbandingan antara putaran pahat dan benda kerja berakibat kepada titik pada pahat putar dan benda kerja tidak bertemu kembali di titik yang sama dalam satu putaran pernuh. Sehingga mengakibatkan aus yang terjadi pada pahat putar tidak seragam di sepanjang sisi potong pahat putar.

\section{KESIMPULAN}

Mekanisme aus yang terjadi pada proses pemesinan paduan magnesium menggunakan sistem pahat putar secara dominan adalah jenis aus abrasif di sepanjang keliling mata pahat. Jenis aus tersebut sudah tampak sejak awal pemotongan dan meningkat luasannya hingga di akhir waktu pemotongan. Aus abrasif tersebut disebabkan oleh gesekan permukaan mata pahat putar dengan partikel tajam hingga menggores permukaan ujung pahat. Fenomena aus pahat putar yang terjadi menunjukan bahwa aus tidak seragam di sepanjang ujung mata pahat (sekeliling mata pahat). Hal tersebut disebabkan oleh rasio antara putaran pahat dan benda kerja tidak sama. Bahkan keadaaan tersebut menyebabkan run out pada saat proses pemotongan.

\section{PERNYATAAN TERIMAKASIH}

Terima kasih diucapkan kepada Lembaga Penelitian dan Pengabdian kepada Masyarakat Universitas Lampung yang telah memberikan fasilitas dan pembiayaan penelitian ini, sehingga dapat berjalan dengan baik hingga ke tahap akhir.

\section{DAFTAR PUSTAKA}

[1] PADMANAHAN, G., BALASUBRAMANIANA, V., MADHUSUDHAN REDD, G., Fatigue crack growth behaviour of pulsed current gas tungsten arc, friction stir and laser beam welded AZ31B magnesium alloy joints, Centre for Materials Joining \& Research (CEMAJOR), Department of Manufacturing Engineering, Annamalai University, Annamalai Nagar 608002, India, 2013.

[2] IBRAHIM, G.A., "Identifikasi Nilai Kekasaran Permukaan pada Pemesinan Paduan Magnesium", Jurnal Mechanical, Vol 5, no 1, 11, 2014.

[3] MAHRUDI, HARIS, YANUAR, B., Rancang Bangun Aplikasi Thermovision Untuk Pemetaan Distribusi Temperatur Dan Permulaan Penyalaan Magnesium Pada Pembubutan Kecepatan Tinggi, Jurusan Teknik Mesin. Universitas Lampung, Bandar Lampung, 2013.

[4] HARUN, S., "Cutting Temperature Measurement in Turning with Actively Driven Rotary Tool”, Key Engineering Materials, Vol. 389-390, pp. 138-14, 2009.

[5] CHRISTOPHER, K. S., VINCE, K., HODGSON, M. A., "Biodegradable Surgical Implants based on Magnesium Alloys”, IOP Conference Series Materials Science and Engineering 4, Vol. 1, 2016.

[6] PENG, W., LILI, T., "Surface Modification on Biodegradable Magnesium Alloys as Orthopedic Im- 
plant Materials to Improve the Bio-Adaptability”, Journal of Materials Science \& Technology, Vol. 32, No. 9, pp. 827-834, 2016.

[7] HARUN, S., YANUAR, B., Peningkatan Produktifitas dan Pengendalian Temperatur Pengapian Pemesinan Magnesium Dengan Sistem Pahat Putar (Rotary Tool System) dan Pendingin Udara (Air Cooling), Universitas Lampung, Bandar Lampung, 2012.

[8] HARYANTO, B., Kajian Temperatur Pemotongan Pemesinan Bubut Menggunakan Pahat Potong Berputar (rotary cutting tool) Pada Material Paduan Magnesium AZ31, Laporan Tugas Akhir, Universitas Lampung, 2015.

[9] IBRAHIM, G.A., PULUNGAN, A. I., BURHANUDDIN, Y., "Unjuk Kerja Vortex Tube Cooler Pada Pemesinan Baja ST41", Jurnal Fema, Vol. 1, No. 4, 2013.

[10] TONSHOFF, H. K., DENKENA, B., Technology of magnesium and magnesium alloys, 2004

[11] KEIICHI, KAWATA, 2015. "Tool Wear in Turning of Inconel 718 with Rotary Cutting Tool", Proceedings Precision Engineering, 2015.

[12] IBRAHIM, G.A., ARINAL, H., JAMIATUL, A., KMAL. "Keausan Mata Pahat Karbida Pada Pemesinan Inconel 718 Menggunakan Pelumas Berkwantitas Minimun”, Proceeding Seminar Nasional Teknik Mesin XV. Bandung, 2016.

[13] LUO, X., CHENG, K., HOLT, T., LIU, X., "Modeling flank wear of carbide tool insert in metal cutting", 15th International Conference on Wear. Vol. 259, pp. 1235-1240, 2016.

[14] IBRAHIM, G.A., BURHANUDDIN, Y., CHE HARON, C.H., GHANI, J.A., ARIFFIN, A. K., YASIR, A., EL-MAGHRIBI, N.H., "The Effects of CBN Cutting Tool Grades on the Tool Life and Wear Mechanism When Dry Turning of Titanium Alloy", Asian International Journal of Science and Technology in Production and Manufacturing. Vol. 1, No.2, pp. 105-110, 2008.

[15] KATO, S., YAMAGUCHI, K., NAKAMURA, T., "A study of rotary shaving by die type cutting tool", Proceedings of the twenty third international machine tool design and Research Conference, 2016.

[16] MURAT K., ERHAN, A., "Effects of process parameters on surface quality in turning of mild steel with rotary cutting tool”, Advance Material Research. Vol. 445, pp. 137, 2014. 